\title{
Immunohistochemical Expression of Cell Cycle Proteins E2F-1, Cdk-2, Cyclin E, p27 kip1, and Ki-67 in Normal Placenta and Gestational Trophoblastic Disease
}

\author{
Maria Olvera, M.D., Selena Harris, M.D., Charles A. Amezcua, M.D., Althea McCourty, B.S., \\ Sherif Rezk, M.D., Charles Koo, M.D., Juan C. Felix, M.D., Russell K. Brynes, M.D. \\ Departments of Pathology (MO, CAA, AM, SR, JCF, RKB) and Obstetrics and Gynecology (SH), Los Angeles \\ County + University of Southern California Healthcare Network, Los Angeles, California; and Department \\ of Pathology (CK), Kaiser Permanente Hospital, Los Angeles, California
}

The role of cell cycle protein expression in gestational trophoblastic disease is poorly understood. In this study we investigated the immunostaining patterns of $G_{1}$ restriction point and $G_{1}-S$ regulatory proteins E2F-1, Cdk2, cyclin E, p27 ${ }^{\mathrm{kip} 1}$, and the proliferation marker Ki-67 on routinely processed sections of 29 hydatidiform moles (10 partial moles and 19 complete moles, including 9 persistent moles), 7 choriocarcinomas, and 7 normal placentas. Ki-67 trophoblast staining decreased with increasing gestational age of the placenta, and showed maximal expression in gestational trophoblastic disease. Cyclin-dependent kinase activity, as reflected by Cdk2 expression patterns, also decreased with placental maturation. E2F-1 was uniquely expressed by trophoblasts of moles and choriocarcinoma. Cyclin E was maximally expressed by complete moles and choriocarcinomas, and showed an inverse relationship with the cyclin-dependent kinase inhibitor $\mathbf{p} 27^{\mathrm{kip} 1}$. Abnormal trophoblastic proliferations may be mediated through interactions of Cdk-2, E2F-1, cyclin E, and p27 ${ }^{\mathrm{kip1}}$. Overexpression of cyclin $\mathrm{E}$ was associated with more aggressive forms of gestational trophoblastic disease. However, we did not find distinguishing features between complete moles that spontaneously resolved after evacuation and persistent moles that required chemotherapy. The different expression patterns of cyclin E and E2F-1 in partial and complete moles may be useful in distinguishing these two entities. Furthermore, loss of p27 $7^{\text {kip1 }}$ in malignant trophoblast may represent a necessary step in the development of choriocarcinoma.

Copyright (C) 2001 by The United States and Canadian Academy of Pathology, Inc.

VOL. 14, NO. 10, P. 1036, 2001 Printed in the U.S.A.

Date of acceptance: June 6, 2001.

Address reprint requests to: Russell K. Brynes, M.D., USC Department of Pathology, 2011 Zonal Avenue HMR 209, Los Angeles, CA 90033; e-mail: Brynes@hsc.usc.edu; fax: 323-226-2686.
KEY WORDS: Cdk2, Choriocarcinoma, Cyclin E, E2F-1, Ki-67, p27 ${ }^{\text {kip1 }}$, Trophoblast.

Mod Pathol 2001;14(10):1036-1042

Cell cycle progression is regulated by the coordinated interactions of a variety of proteins, which include E2F-1, cyclin-dependent kinases (Cdks), cyclin E, and p27 ${ }^{\text {kipl }}$ (1-12). The retinoblastoma protein $(\mathrm{pRb})$ in its active, hypophosphorylated state is an inhibitor of cell cycle progression from $G_{1}$ to $S$ phase $(4,6)$. Cyclin E as a complex with Cdk-2 regulates the $G_{1}-S$ transition by phosphorylation/ inactivation of $\mathrm{pRb}$, which releases E2F-1 $(3,13)$. Free E2F-1 mediates $\mathrm{G}_{1}$-S progression by forming complexes with other proteins, which ultimately bind to promoter sequences of genes necessary for DNA replication and cell cycle control (9). E2F-1 binding sites are present in the promoter region of the cyclin E gene (5). The activity of the promoter is in turn negatively regulated by $\mathrm{pRb}$. A positivefeedback loop in late $G_{1}$ phase helps to ensure continued cyclin $\mathrm{E}$ expression and $\mathrm{pRb}$ inactivation. The Cdk inhibitor p2 $7^{\mathrm{kip} 1}$ functions as a negative regulator of $\mathrm{G}_{1}$ progression by binding to cyclin E-Cdk2 complexes (14-16).

Gestational trophoblastic disease (GTD) encompasses a heterogeneous group of lesions, including partial and complete hydatidiform moles and choriocarcinoma, placental site trophoblastic tumor, epithelioid trophoblastic tumor, placental site nodule and exaggerated placental site. All are characterized by abnormal trophoblast proliferation (17). Partial and complete moles arise from abnormal fertilization resulting in excess paternal genomic material, and have the potential for persistent GTD including metastasis (18). Despite morphologic differences, it may at times be difficult to distinguish partial from complete moles $(17,19)$. Choriocarcinoma is a highly malignant epithelial tumor that may arise from the trophoblast of 
any type of gestational event, most commonly in a complete mole.

Recent studies have shown that trophoblast proliferation as determined by Ki-67 and $G_{1}$ cyclin immunostaining, decreases during normal placental development (20-22). Relatively little is known, however, about cell cycle protein expression in GTD. In this study we have investigated the immunostaining patterns of the $G_{1}$ restriction point and $\mathrm{G}_{1}-\mathrm{S}$ regulatory proteins E2F-1, cyclin E, Cdk2, p $27^{\mathrm{kip} 1}$, and the proliferation marker Ki-67 in normal placentas, partial and complete moles (including persistent moles), and choriocarcinoma.

\section{MATERIALS AND METHODS}

\section{Tissues}

Twenty-nine hydatidiform moles (10 partial and 19 complete), 7 choriocarcinomas, and 7 placentas (3 first trimester, 2 second trimester, and 2 third trimester) were collected from the surgical pathology files of the Departments of Pathology at the Women's and Children's Hospital of Los Angeles County + University of Southern California Healthcare Network and the Kaiser Foundation Hospital, Los Angeles. All cases had been fixed in $10 \%$ buffered formalin and were routinely processed and embedded in paraffin. Flow cytometric ploidy analysis data were available on six partial and one complete mole.

\section{Immunohistochemical Methods}

A monoclonal antibody reactive with E2F-1 protein (clone KH95, Santa Cruz Biotechnology, Inc., Santa Cruz, CA) was used at 1:50 dilution. Cyclin E was detected with the monoclonal antibody HE12 (Pharmingen, San Diego, CA), used at 1:50 dilution. A monoclonal antibody that identified p2 $7^{\mathrm{kip} 1}$ (clone 57, Transduction Laboratories, Lexington, $\mathrm{KY}$ ) was used at a dilution of 1:200. The monoclonal antibody reactive with Cdk2 (2B6, Neomarkers, Fremont, CA) was used at 1:100 dilution. For demonstration of the Ki-67 nuclear-associated proliferation antigen, the monoclonal antibody MIB-1 (Immunotech, Westbrook, ME) was used at 1:100 dilution. Control sections were immunostained un- der identical conditions substituting the primary antibody with an irrelevant antibody (CD20, L26, DAKO, Carpenteria, CA) or with buffer solution.

Tissue sections baked at 56 degrees $\mathrm{C}$ for $60 \mathrm{~min}$ utes, deparaffinized with xylene, and rehydrated with graded ethanols to distilled water. Epitope retrieval was carried out for 15 minutes in boiling $0.01 \mathrm{~mol} / \mathrm{L}$ citrate buffer at pH 6.0 (E2F-1, MIB-1, Cdk2, and p2 $7^{\text {kipl}}$ ), or $0.001 \mathrm{~mol} / \mathrm{L}$ EDTA buffer at pH 8.0 (cyclin E). Reactivity was detected with an avidin-biotin immunoperoxidase detection system employing $3^{\prime}, 3^{\prime}$ diaminobenzidine tetrahydrochloride dihydrate as the chromogen (Vector Labs, Burlingame, CA).

\section{Evaluation of Staining}

For all the markers used in this study, only homogeneous nuclear staining was considered positive. Occasional cytoplasmic staining was considered nonspecific, and was not included in our evaluation. The sections were initially scanned at low power to determine the areas that were evenly labeled. All cells exhibiting a brown nuclear reaction product were interpreted as positive, regardless of staining intensity.

Scoring estimates were based on the number of stained trophoblast nuclei: 0 (no staining), $1+$ (1$10 \%), 2+(11-25 \%), 3+(26-50 \%)$, and $4+$ ( more than $50 \%$ ). The cases were evaluated independently by four of the authors (MO, SR, JCF, and RKB), and discrepancies in estimation were reconciled by concurrent review using a multi-headed microscope. Scoring of normal placental tissue immunostains was performed on the trophoblast of placental villi. Proliferating trophoblast of the trophoblastic columns in implantation villi, where present were not included in our assessment.

\section{RESULTS}

Immunostaining demonstrated a spectrum of expression patterns in normal placenta and GTD (Table 1). The number of trophoblast nuclei stained for Ki-67 decreased with increasing gestational age of the placenta. The staining was limited to the basal layer of villous cytotrophoblast, which is composed of mitotically active, mononuclear cells. The termi-

TABLE 1. Expression of Cell Cycle Proteins in Gestational Trophoblastic Disease and Normal Placenta

\begin{tabular}{|c|c|c|c|c|c|}
\hline Trophoblast & Ki-67 & E2F-1 & Cdk2 & Cyclin E & $\mathrm{p} 27^{\mathrm{kip} 1}$ \\
\hline $1^{\text {st }}$ trimester placenta & $2+$ & 0 & $3+$ & $2+$ & $4+$ \\
\hline $2^{\text {nd }}$ trimester placenta & $2+$ & 0 & $2+$ & $2+$ & $2+$ \\
\hline $3^{\text {rd }}$ trimester placenta & $1+$ & 0 & $2+$ & $2+$ & $1+$ \\
\hline Partial mole & $3+$ & $1+$ & $4+$ & $2+$ & $4+$ \\
\hline Complete mole & $4+$ & $2+$ & $4+$ & $4+$ & $3+$ \\
\hline Persistent complete mole & $4+$ & $2+$ & $4+$ & $4+$ & $3+$ \\
\hline Choriocarcinoma & $4+$ & $2+$ & $4+$ & $4+$ & $1+$ \\
\hline
\end{tabular}

0 , no staining; $1+, 1-10 \%$ positive cells; $2+, 11-25 \%$ positive cells; $3+, 26-50 \%$ positive cells; $4+,>50 \%$ positive cells. 
nally differentiated syncytiotrophoblast cells, which are larger multinucleated cells, were not stained. Moles and choriocarcinoma contained the largest numbers of positively stained cells (Fig. 1). Complete moles and choriocarcinoma consistently demonstrated more than $50 \%(4+)$ positive cells, primarily in the mononuclear trophoblast.

In normal placenta, Cdk2 was maximally expressed by first trimester trophoblast, and decreased with gestational age. The staining was predominantly found in the villous cytotrophoblast

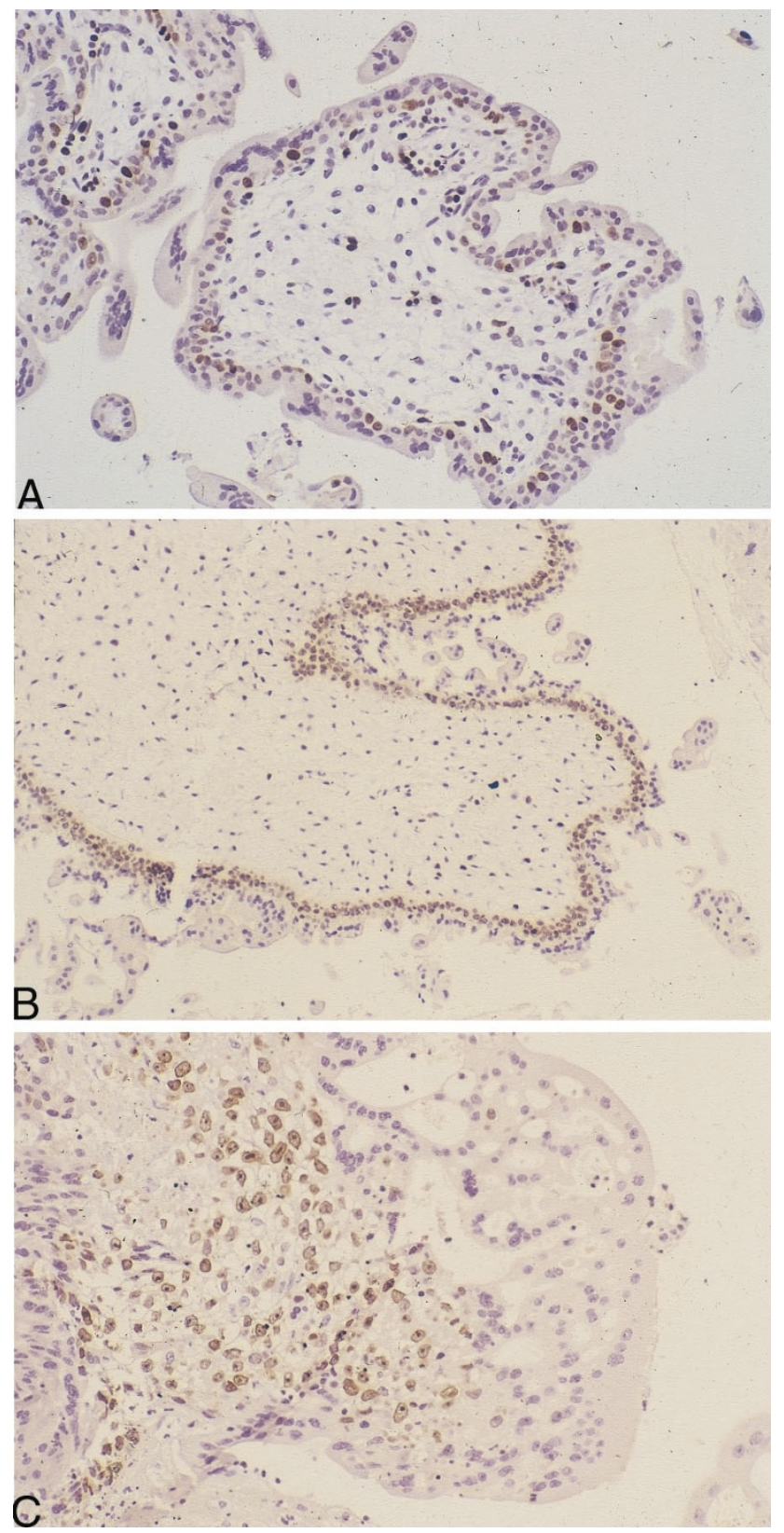

FIGURE 1. A, Strong Ki-67 staining (3+) primarily labels basal cytotrophoblast nuclei surrounding villi of a partial mole. B, Strong staining $(4+)$ is limited to villous and extra-villous cytotrophoblast nuclei of a complete mole. C, Cytotrophoblast nuclei of choriocarcinoma show very strong expression $(4+)$.

Syncytiotrophoblastic cells were generally negative (Immunoperoxidase, $\times 200$ ). basal layer. In all cases of GTD, including choriocarcinoma, Cdk2 was strongly expressed $(4+)$.

E2F-1 was not detectable in placental trophoblast at any gestational age. Partial moles showed less than $10 \%$ positively stained trophoblast $(1+)$. However, complete moles and choriocarcinomas demonstrated moderate expression of E2F-1 (2+) (Fig. 2). In complete moles, both persistent and nonpersistent, staining was predominantly seen in the extravillous trophoblast and the villous cytotrophoblast basal layer.

Cyclin E was uniformly expressed at moderate levels $(2+)$ in all stages of normal placental development. Staining was limited to the basal cytotrophoblast nuclei surrounding the villi. The syncytiotrophoblast was generally negative. The staining pattern found in partial moles was similar to that of normally developing placental trophoblast and was generally limited to the cytotrophoblast basal layer (Fig. 3A). In addition, extravillous clusters of intermediate trophoblast and cytotrophoblast were often positive. Complete moles and choriocarcinoma expressed the largest number of positively stained cells $(4+)$ (Fig. 3, B-C). The persistent moles showed diffuse staining of all cells in the villous trophoblast, including syncytiotrophoblast, as well as extravillous clusters.

p $27^{\text {kip } 1}$ was strongly expressed in the first trimester normal placenta and showed a marked decline with gestational maturation. It was overexpressed in partial moles, moderately expressed in complete moles, and only minimally expressed in choriocarcinoma (Fig. 4, A-C). In partial moles, staining of the basal cytotrophoblast layer was minimal or absent, whereas the superficial layers and syncytiotrophoblast cells were positive. In complete moles and choriocarcinoma, the cytotrophoblast had minimal staining. The positive nuclei were almost exclusively found in the syncytiotrophoblast. The persistent moles demonstrated a mixed cytotrophoblast and syncytiotrophoblast staining pattern, often sparing the basal layer.

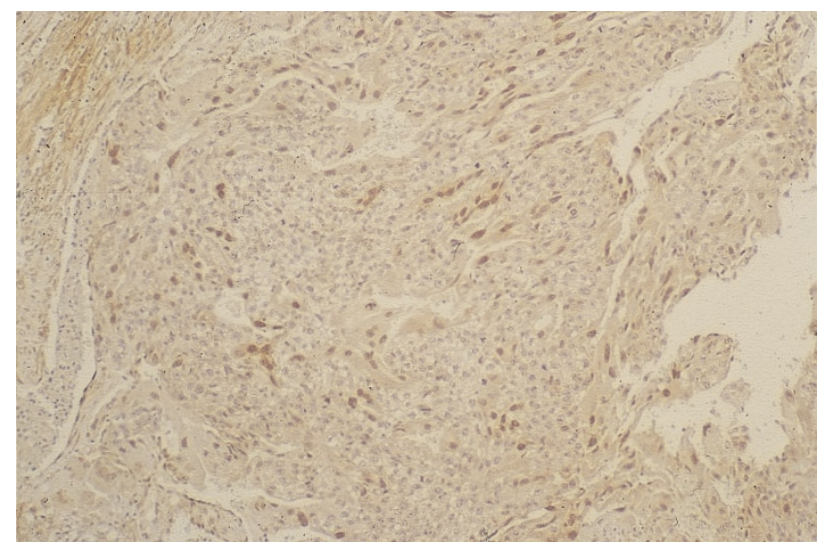

FIGURE 2. Moderate E2F-1 expression (2+) was seen in choriocarcinoma (Immunoperoxidase, $\times 100$ ). 


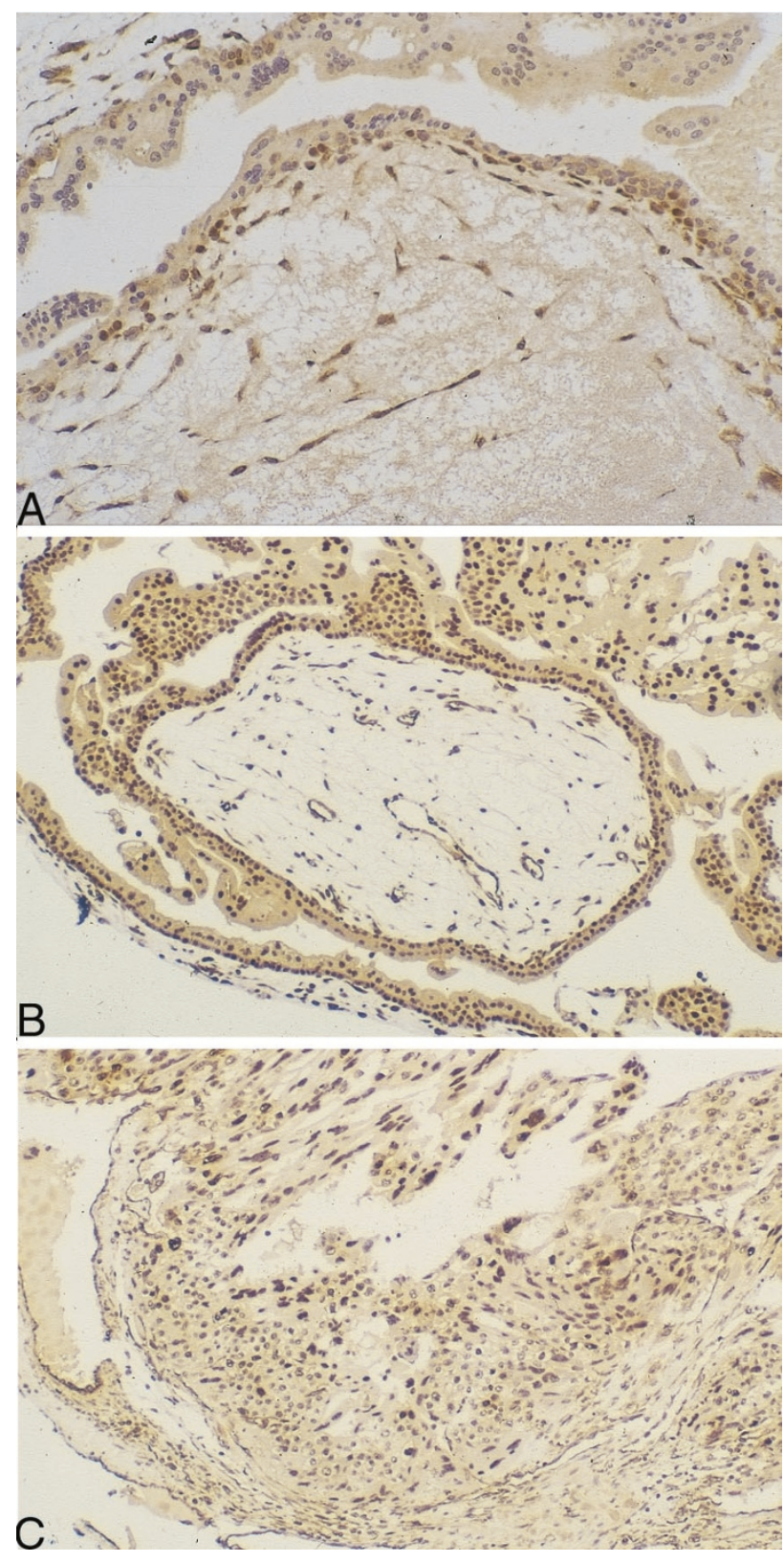

FIGURE 3. A, Moderate cyclin E staining $(2+)$ is seen in the villous cytotrophoblast of a partial mole. B, Strong staining (4+) was found in complete moles, and in (C) choriocarcinoma (Immunoperoxidase, $\times 200)$.

Paraffin-embedded blocks from seven moles (six partial and one complete) were submitted for flow cytometric analysis to supplement morphologic assessment. A triploid DNA index supported the diagnosis of partial mole in all six cases examined. A diploid index with a tetraploid population, confirmed the diagnosis of complete mole in the remaining case.

\section{DISCUSSION}

The purpose of this study was to survey the expression patterns of the key cell cycle checkpoint proteins Ki-67, E2F-1, cyclin E, Cdk2, and p27 ${ }^{\mathrm{kip} 1}$
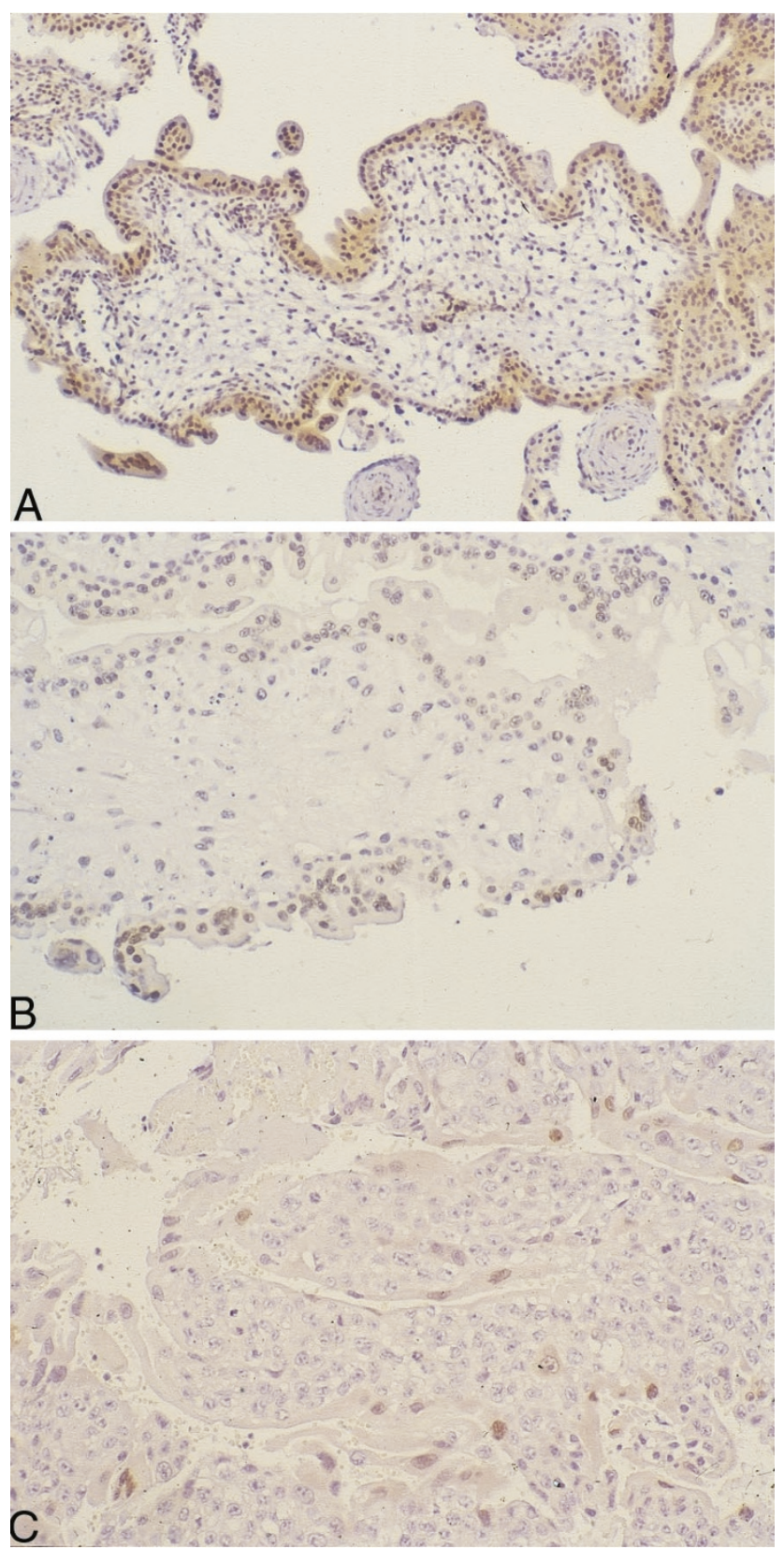

FIGURE 4. A, Strong p $27^{\mathrm{kip} 1}$ staining $(4+)$ of superficial villous trophoblast and syncytiotrophoblast was seen in partial moles, while moderate staining ( $3+$ ) was detected in complete moles (B). C, Only rare $(1+)$ syncytiotrophoblastic cells stained for $\mathrm{p} 27^{\mathrm{kip} 1}$ in choriocarcinoma (Immunoperoxidase, $\times 200$ ).

by immunohistochemistry in GTD and normal placentas.

We observed a decrease in Ki-67-defined trophoblast proliferation as normal gestation progressed. This finding has been previously reported, although the studies have generally been limited to comparisons of first and third trimester placentas (23). We observed higher levels of Ki-67 immunoreactivity in first and second trimester placental villi than in third trimester specimens. The largest numbers of proliferating cells were seen in the abnormally developing trophoblast of complete moles, including 
persistent moles, and choriocarcinomas. Partial moles contained fewer positive cells. Several reports have noted differences between molar and non-molar trophoblast, as well as differences between partial and complete moles, and have suggested the evaluation of Ki-67 as a useful adjunct to morphologic criteria for separating complete from partial moles (24-26). We did not find differences in proliferative activity between persistent and spontaneously resolving cases of complete mole.

The $\mathrm{pRb} / \mathrm{E} 2 \mathrm{~F}-1$ pathway is essential in the passage of cells through the $G_{1}$ phase of the cell cycle. Immunostaining for the presence of $\mathrm{pRb}$ often provides ambiguous information, because methods to accurately distinguish between partially phosphorylated and completely dephosphorylated states are not currently available. Furthermore, in addition to down-regulating cell-cycle progression, $\mathrm{pRb}$ has also been found to play a key role in promoting cell cycle exit during terminal embryonic differentiation in many tissues $(11,27)$. The expression patterns of cyclin E and Cdk2 would indeed suggest that pRb plays a role in trophoblastic proliferations, because these proteins are known to phosphorylate/inactivate $\mathrm{pRb}$ and allow cell cycle progression.

Moderate expression levels of both Cdk2 and cyclin E were found throughout placental development. In theory, one would expect E2F-1 levels to parallel the appearance of cyclin E-Cdk2 complexes, as E2F-1 is released from pRb. The absence of E2F-1 in normal placental trophoblast may simply reflect low levels that were undetectable by our methods. Alternatively in some systems, developmental control of cell-cycle exit during differentiation has been shown to require pRb but not E2F-1 (11). In the developing murine hematopoietic and nervous systems, the role of $\mathrm{pRb}$ in cell-cycle exit during differentiation occurs independently of E2F-1 (11). This function is believed to occur through the induction of tissue-specific survival factors and other anti-apoptotic agents. E2F-1 was not detected in the developing trophoblast of normal placenta suggesting that it may not be required for cellular proliferation in normal development.

As would be expected, the highest levels of Cdk2 and cyclin $\mathrm{E}$ were found in the uncontrolled trophoblastic proliferations of GTD. In addition, E2F-1 became detectable in the cytotrophoblast of partial moles, whereas complete moles and choriocarcinoma demonstrated moderate levels of expression in mononuclear cells (cytotrophoblast and intermediate trophoblast). Gene amplification of E2F-1 with increased expression of E2F-1 mRNA has been observed in gastric and colorectal tumors compared with their corresponding non-neoplastic mucosas $(28,29)$. The appearance of E2F-1 in partial and complete moles would indicate that it plays an important role in neoplastic trophoblastic proliferations.

Cell proliferation is influenced by the activation of Cdks that occurs through cyclin binding. The cyclin E-Cdk2 complex is essential for $\mathrm{G}_{1}$-S progression. As reported by others, we found cyclin E expression at moderate levels throughout normal placental development $(20,21,30,31)$. We did not detect differences in the expression of cyclin $\mathrm{E}$ at the different stages of normal placental development. In most cases, the staining was limited to the villous cytotrophoblast basal layer. Studies of third trimester placenta have previously shown that the highest levels of cyclin E expression are found in the cytotrophoblast layer (30). In addition, correlation between cyclin $\mathrm{E}$ and proliferative activity, as reflected by Ki-67 staining has been observed in normal placental development (20).

In our study, we found similar levels of cyclin $\mathrm{E}$ overexpression in both complete moles and choriocarcinoma. Kim and colleagues, who looked exclusively at cyclin E and compared hydropic placentas to GTD (32), recently reported overexpression of cyclin E in GTD. However, they found higher cyclin E levels in choriocarcinoma than in complete moles. Scoring methodology might account for this difference. We found that partial moles did not exhibit the same level of cyclin E overexpression found in complete moles and choriocarcinoma. Kim et al. also noted decreased levels in partial moles, yet they were not able to demonstrate statistical significance. In general, we observed parallel expression of Cdk2 with cyclin E, supporting the expected interaction of these two regulators as a complex. Overexpression of cyclin E has been reported in a variety of malignancies, including squamous cell carcinomas of lung and cervix, acute lymphoblastic leukemia, and in gastric adenocarcinoma, especially in deeply invasive tumors (32-37). Our findings support an important role for cyclin $\mathrm{E}$ in the development of GTD, including choriocarcinoma. In our study, we included a subset of nine persistent complete moles that behaved more aggressively, but were unable to find any differences from those that spontaneously resolved after evacuation.

Furthermore, in all cases of GTD, cyclin E and E2F-1 levels were expressed in a parallel fashion. We detected moderate levels of E2F-1 and strong overexpression of cyclin $\mathrm{E}$ in complete moles and choriocarcinoma. The overexpression of cyclin $\mathrm{E}$ may be related to increased binding and activation by E2F-1 to the cyclin E gene promoter region (5).

High concentrations of Cdk2/cyclin E complexes are known to phosphorylate p2 $7^{\text {kip } 1}$ complexes, resulting in its degradation (14-16). In our study, the lowest cyclin E levels in partial moles were associated with the highest levels of $\mathrm{p} 27^{\mathrm{kip} 1}$, and in cho- 
riocarcinoma overexpression of cyclin E was associated with a marked reduction of $\mathrm{p} 27^{\mathrm{kip} 1}$. An inverse relationship between cyclin $\mathrm{E}$ and $\mathrm{p} 27^{\mathrm{kip} 1}$ has been found in a variety of neoplasms, including thyroid and breast carcinomas, and non-Hodgkin lymphoma (38-41). Although loss of p27 $7^{\text {kipl }}$ has been reported in various tumors, it has not been previously reported in choriocarcinoma. The role of cyclin $\mathrm{E}$ in facilitating cell cycle progression in complete moles and choriocarcinoma seems to be dependent on its ability to down-regulate the inhibitor $\mathrm{p} 27^{\mathrm{kip} 1}$. Our findings suggest that loss of $\mathrm{p} 27^{\mathrm{kip} 1}$ tumor suppressor activity may be a necessary step in the development of choriocarcinoma.

In summary, these data indicate that trophoblast proliferation in moles may be regulated by interactions between cdk2, cyclin E, and E2F-1. Higher levels of cyclin E and E2F-1 expression in complete moles may provide a useful adjunct for separating these processes from partial moles. Our data also included a subset of persistent moles, which behave in a more aggressive fashion. We did not find any differences in immunostaining patterns between persistent moles and those that spontaneously resolved after evacuation. A previous study of cyclin $\mathrm{E}$ in GTD suggested that cyclin E overaccumulation might play a role in malignant transformation of trophoblasts (32). Our data support this interpretation, and furthermore associate overexpression of cyclin E with a loss of $\mathrm{p} 27^{\mathrm{kip} 1}$.

\section{REFERENCES}

1. Kranenburg O, van der Eb AJ, Zantema A. Cyclin-dependent kinases and $\mathrm{pRb}$ : regulators of the proliferationdifferentiation switch. FEBS Lett 1995;367:103-6.

2. Morgan DO. Principles of CDK regulation. Nature 1995;374: 131-4.

3. Pines J. Cyclin and cyclin-dependent kinases: a biochemical view. Biochem J 1995;308:697-711.

4. Hatakeyama M, Weinberg RA. The role of RB in cell cycle control. Prog Cell Cycle Res 1995;1:9-19.

5. Geng Y, Eaton EN, Picon M, Roberts JM, Lundberg AS, Gifford A, et al. Regulation of cyclin E transcription by E2Fs and retinoblastoma protein. Oncogene 1996;12:1173-80.

6. Zarkowska T, Mittnacht S. Differential phosphorylation of the retinoblastoma protein by G1/S cyclin-dependent kinases. J Biol Chem 1997;272:12738-46.

7. Helin K, Harlow E, Fattaey A. Inhibition of E2F-1 transactivation by direct binding of the retinoblastoma protein. Mol Cell Biol 1993;13:6501-08.

8. Johnson DG, Schneider-Broussard R. Role of E2F in cell cycle control and cancer. Front Biosci 1998;3:d447-8.

9. Helin K. Regulation of cell proliferation by the E2F transcription factors. Curr Opin Genet Dev 1998;8:28-35.

10. Lundberg AS, Weinberg RA. Functional inactivation of the retinoblastoma protein requires sequential modification by at least two distinct cyclin-cdk complexes. Mol Cell Biol 1998;18:753-61.

11. Macleod K. pRb and E2F-1 in mouse development and tumorigenesis. Curr Opin Genet Dev 1999;9:31-9.

12. Watanabe G, Albanese C, Lee RJ, Reutens A, Vairo G, Henglein B, et al. Inhibition of cyclin D1 kinase activity is asso- ciated with E2F-mediated inhibition of cyclin D1 promoter activity through E2F and Sp1. Mol Cell Biol 1998;18:3212-22.

13. Mumberg D, Haas K, Moroy T, Niedenthal R, Hegemann JH, Funk M, et al. Uncoupling of DNA replication and cell cycle progression by human cyclin E. Oncogene 1996;13:2493-7.

14. Xu X, Nakano T, Wick S, Dubay M, Brizuela L. Mechanism of Cdk2/Cyclin E inhibition by p27 and p27 phosphorylation. Biochem 1999;38:8713-22.

15. Montagnoli A, Fiore F, Eytan E, Carrano AC, Draetta GF, Hershko A, et al. Ubiquitination of p27 is regulated by Cdkdependent phosphorylation and trimeric complex formation. Genes Dev 1999;113:1181-9.

16. Nguyen H, Gitig DM, Koff A. Cell-free degradation of p27(kip1), a G1 cyclin-dependent kinase inhibitor, is dependent on CDK2 activity and the proteasome. Mol Cell Biol 1999;19:1190-201.

17. Mazur MT, Kurman RJ. Gestational trophoblastic disease and related lesions. In: Kurman RJ, editors. Blaustein's pathology of the female genital tract. 4th ed. New York: Springer-Verlag; 1994. p. 1049-93.

18. Fox H. Differential diagnosis of hydatidiform moles. Gen Diagn Pathol 1997;143:117-25.

19. Sumithran E, Cheah PL, Susil BJ, Looi LM. Problems in the histological assessment of hydatidiform moles: a study on consensus diagnosis and ploidy status by fluorescent in situ hybridization. Pathology 1996;28:311-5.

20. Bamberger A, Sudahl S, Bamberger CM, Schulte HM, Loning T. Expression patterns of the cell-cycle inhibitor p27 and the cell-cycle promoter cyclin $\mathrm{E}$ in the human placenta throughout gestation: implications for the control of proliferation. Placenta 1999;20:401-6.

21. DeLoia JA, Burlingame JM, Krasnow JS. Differential expression of G1 cyclins during human placentogenesis. Placenta 1997;18:9-16.

22. Palazon LS, Davies TJ, Gardner RL. Translational inhibition of cyclin B1 and appearance of cyclin D1 very early in the differentiation of mouse trophoblast giant cells. Mol Hum Reprod 1998;4:1013-20.

23. Cheung AN, Ngan HY, Collins RJ, Wong YL. Assessment of cell proliferation in hydatidiform mole using monoclonal antibody MIB1 to Ki-67 antigen. J Clin Pathol 1994;47:601-4.

24. Schammel DP, Bocklage T. p53, PCNA, and Ki-67 in hydropic molar and nonmolar placentas: an immunohistochemical study. Int J Gynecol Pathol 1996;15:158-66.

25. Cheville JC, Robinson R, Benda JA. Evaluation of Ki-67 (MIB-1) in placentas with hydropic change and partial and complete hydatidiform mole. Pediatr Pathol Lab Med 1996; 16:41-50.

26. Ostrzega N, Phillipson J, Liu P. Proliferative activity in placentas with hydropic change and hydatidiform mole as detected by Ki-67 and proliferating cell nuclear antigen immunostaining. Am J Clin Pathol 1998;110:776-81.

27. Lee EY, Hu N, Yuan SS, Cox LA, Bradley A, Lee WH, et al. Dual roles of the retinoblastoma protein in cell cycle regulation and neuron differentiation. Genes Dev 1994;8:200821.

28. Suzuki T, Yasui W, Yokozaki H, Naka K, Ishikawa T, Tahara E. Expression of the E2F family in human gastrointestinal carcinomas. Int J Cancer 1999;81:535-8.

29. Yasui W, Naka K, Suzuki T, Fujimoto J, Hayashi K, Matsutani $\mathrm{N}$, et al. Expression of p27kip1, cyclin E and E2F-1 in primary and metastatic tumors of gastric carcinoma. Oncol Rep 1999; 6:983-87.

30. McKenzie PP, Foster JS, House S, Bukovsky A, Caudle MR, Wimalasena J. Expression of G1 cyclins and cyclindependent kinase-2 activity during terminal differentiation of cultured human trophoblast. Biology of Reprod 1998;58: 1283-9. 
31. MacAuley A, Cross JC, Werb Z. Reprogramming, the cell cycle for endoreduplication in rodent trophoblast cells. Mol Biol Cell 1998;9:795-807.

32. Kim YT, Cho NH, Ko JH, Yang WI, Kim JW, Choi EK, et al. Expression of cyclin E in placentas with hydropic change and gestational trophoblastic diseases: implications for the malignant transformation of trophoblasts. Cancer 2000;89: 673-9.

33. Keyomarsi K, Herliczek TW. The role of cyclin E in cell proliferation, development and cancer. Prog Cell Cycle Res 1997;3:171-91.

34. Donnellan R, Chetty R. Cyclin E in human cancers. FASEB J 1999;13:773-80.

35. Lonardo F, Rusch V, Langenfeld J, Dmitrovsky E, Klimstra DS. Overexpression of cyclins D1 and $\mathrm{E}$ is frequent in Bronchial preneoplasia and precedes squamous cell carcinoma development. Cancer Res 1999;59:2470-6.

36. Quade BJ, Park JJ, Crum CP, Sun D, Dutta A. In vivo cyclin E expression as a marker for early cervical neoplasia. Mod Pathol 1998;11:1238-46.
37. Scuderi R, Palucka KA, Pokrovskaja K, Bjorkholm M, Wiman KG, Pisa P. Cyclin E gene expression in relapsed adult acute lymphoblastic leukemias of B-cell lineage. Blood 1996;87: 3360-7.

38. Yasui W, Akama Y, Kuniyasu H, Yokozaki H, Semba S, Shimamoto F, et al. Expression of cyclin $\mathrm{E}$ in human gastric adenomas and adenocarcinomas: correlation with proliferative activity and p53 status. J Exp Ther Oncol 1996;1:88-94.

39. Wang S, Wuu J, Savas L, Patwardhan N, Khan A. The role of cell cycle regulatory proteins, cyclin D1, cyclin E, and p27 in thyroid carcinogenesis. Hum Pathol 1998;29:1304-9.

40. Loden M, Nielsen NH, Roos G, Emdin SO, Landberg G. Cyclin E dependent kinase activity in human breast cancer in relation to cyclin E, p27 and p21 expression and retinoblastoma protein phosphorylation. Oncogene 1999;18:2557-66.

41. Erlanson M, Portin C, Linderholm B, Lindh J, Roos G, Landberg G. Expression of cyclin E and the cyclin-dependent kinase inhibitor p27 in malignant lymphomas-prognostic implications. Blood 1998;92:770-7.

\section{Book Review}

\section{Fuller GN, Goodman JC: Practical Review of Neuropathology, 352 pp, Philadelphia, Lip- pincott Williams \& Wilkins, 2001 (\$69.95).}

Gregory N. Fuller and J. Clay Goodman intended that their book, Practical Review of Neuropathology, provide a conceptual framework of neuropathologic diseases and depict essential elements of specific neurologic diagnoses. The authors envision facilitating fruitful dialogue between the theoretical world of the basic scientist and the practical world of the clinical investigator/practitioner by clarifying neuropathologic topics using fundamental scientific principles. This book is skillfully organized, and perspectives (a logical approach to understanding) and objectives are clearly outlined at the beginning of each chapter. Abundant figures, tables, and photographs precisely illustrate key concepts as they relate to a broad spectrum of specific neuropathologic disorders. A short bibliography at the end of each chapter cites the most significant relevant references for a particular subject.

This review guides the reader to a better understanding of general scientific principles that are the foundation of neuropathologic disease. Medical students and residents studying for board exams will find the format of this book ideal for both learning and reviewing neuropathology. Medical practitioners, researchers, and educators who treat or study neurologic diseases also will appreciate both the substance and style of the presented material. The authors profess that a unifying theme of neuropathology is that all underlying processes can be understood in terms of disorders of cell life (i.e., developmental disease, neoplasia) or cell death (i.e., vascular disease, neurodegenerative disease). Key features of specific neuropathologic diseases and practical pathologic concepts are presented using descriptive text, eloquent tables, succinct figures, and classic photographs of neuroradiologic images, gross specimens, and histologic sections. Practical Review of Neuropathology is an effective, well-illustrated review that is exceptionally readable, using colorful language and subtle humor to keep the reader thoroughly engaged. Neurology, pathology, and neurosurgery residents should consider using this text as their primary study guide during their neuropathology rotations.

\section{Karen SantaCruz \\ University of Kansas School of Medicine \\ Kansas City, Kansas}

